\title{
Design of Dual Band Sleeve Dipole Antenna for Mobile Jammer Applications
}

\author{
Tariq Rahim*, Jiaodong Xu \\ School of Electronic and Information Engineering, Northwestern Polytechnic University, \\ 710129, Shaanxi, Xi'an, China \\ ${ }^{*}$ Corresponding author, e-mail: rahim372@gmail.com
}

\begin{abstract}
A multi band sleeve dipole antenna for jammer application is proposed. The antenna can cover band in which mobile and other wireless devices operate. The design antenna shows very good omnidirectional characteristics and scattering parameter $S 11$ value less than -10db. The dipole is made of two concentric hallow cylinder with different radius and different lengths. The antenna is fed at the center with coaxial cable pass through the bottom cylinder and thus avoids the use of complicated balun network. The impedance bandwidth and the radiation pattern are measured and analyzed both at $900 \mathrm{MHz}$ and 1.8 GHz. The antenna can also be used GSM/DCS/WCDMA/CDMA2000/ TD-SCDMA /WLAN applications at both indoor and outdoor platform.
\end{abstract}

Keywords: jammer, dipole antenna, wireless communication, radome

Copyright $\odot 2015$ Institute of Advanced Engineering and Science. All rights reserved.

\section{Introduction}

The With the increase of wireless technology, communication devices become ubiquitous. Therefore, there is a need of signal scrambler in certain area and under certain conditions. The drastic increase in wireless communication devices particularly cell phone become hazard to a human society. The jammer was first use for military applications to detract the data pass between the transmitter and receiver. As cell phone become an essential part of our daily life, the misuse of these wireless devices increase drastically, particularly in places like conference rooms, law courts, libraries, lecture rooms and worship places. So there is a need to stop the disrupting calls or information leak is to install a wireless jammer to make these places or information secure. The wireless device is nowadays using as an electronic countermeasure device. Moreover, to protect some VIP movements in war effected area jammer play a very important role. In this work we propose a dual band sleeve dipole antenna for jammer application. To use two or more bands into a single device, dual and multi-band antennas play a very important role, because it require less space and having low cost as compared with different antennas operating at different bands. That is why a multi-band sleeve antenna is widely used in mobile communication systems and broadcast systems, primarily due to its omnidirectional pattern and ease of fabrication [1-6]. Different antennas has been proposed such as PIFA antenna [7], loop antenna [8] and slot antenna [9, 10] to provide dual band characteristics. Most of these wide band monopoles and side dipoles antennas based on wire or wireless have very complicated feed system and may require a balanced unbalanced system [10-28]. Among all the end feed sleeve dipole antenna provide far better omni-directional radiation pattern [1, 2]. Coaxial feed sleeve dipole antennas can be design in a very small diameter, due to the in line configuration, which enable them to be used in very sophisticated applications like in cancer therapy, the cancerous tissues can be heated by electromagnetic waves using an external or internal antenna, especially in sensitive regions like brain or prostate tumors [21]. However, in some cases these antennas may require slightly large space in line, but can be used both for indoor and outdoor applications. The dual band dipole antenna can be transformed to any bands based the different lengths and diameter of the dipole and the difference between the radius of the poles. Moreover, the side feed dipole antenna degrade the radiation pattern and also increase the size of the antenna. For these reasons, a simple dual band hollow cylindrical dipole antenna were proposed for GSM application. The antenna have a 
simple feed coaxial feed through the lower hallow pipes and feed the dipole at the center. This feed which have no need for an extra balun have very good omnidirectional radiation characteristics at both $900 \mathrm{MHz}$ and $1800 \mathrm{MHz}$. Furthermore, the antenna shows band notch characteristics from 1-1.7 GHz, this band can be changed according to the application by changing the lengths of poles and varying the diameter of the two concentric poles. Various antenna parameters such as impedance bandwidth, radiation patterns and gain are discussed in this paper. It shows wideband properties which can well meet mobile communications requirements.

In Section 2, the geometry of the dual band sleeve antenna is given. In Section 3, the antenna scattering parameters and radiation characteristics are discussed by plotting the simulation and measured results. The design and applications are concluded in Section 4.

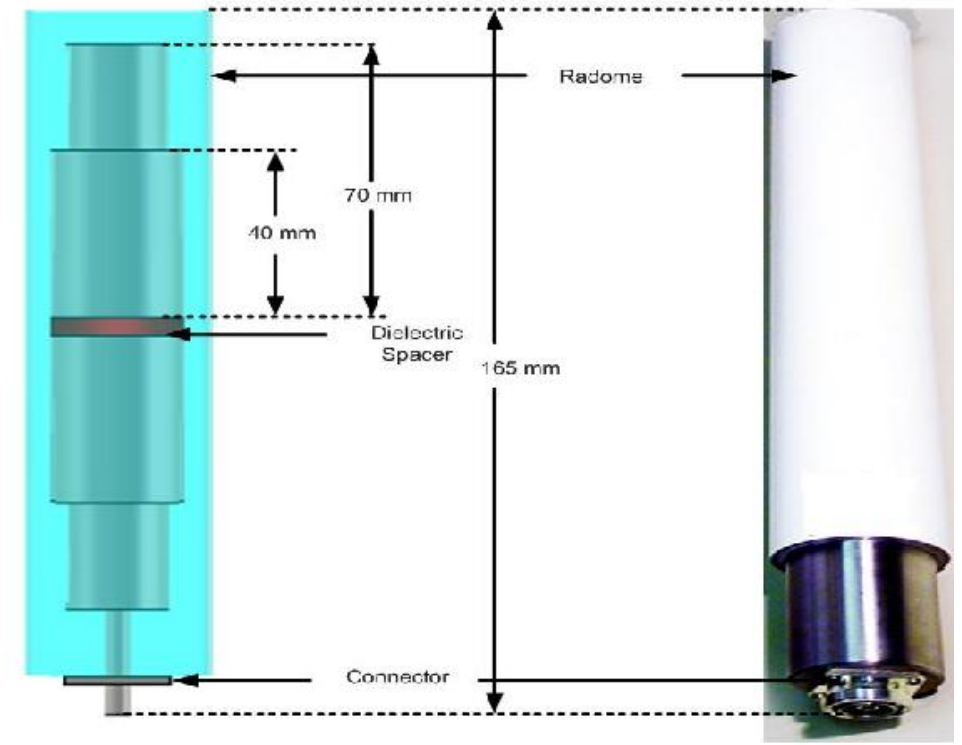

Figure 1. Simulated and fabricated model and dimensions of the proposed antenna

\section{Geometry of the Proposed Sleeve Dipole Antenna}

The structure of the proposed antenna is shown in Figure 1. The radiating part for lower frequency dipole consists of two cylindrical conductors, of which each opposite base is stretched a circular hallow metal tube from the central feed position. Two concentric cylindrical hallow pipes closed at the feed point with base plate and having a higher diameter with the lower frequency cylinder are also there for high frequency bands and band notch characteristics. The difference between the diameter of the two cylinders is adjusted such that a minimum of coupling occur between the two radiation poles. A coaxial cable for inserted for feed inside the lower hallow cylindrical copper conductor and symmetrically excites the sleeve dipole antenna at the center of the base plate. The inner of the coaxial cable is extended through the spacing between the two plates at the bases of each hollow cylinders, and connected to the upper metal plate, and the outer conductor of that is connected to the lower plate. Due to this end feed system there is no need for a balun. Moreover, it is simple to fabricate which further reduce the cost. In contrast to side feed system which form a $T$ require more space and also have distorted radiation pattern. Similarly two more cylindrical conductors with high radius acting as a pole for the upper frequency band. As shown in Figure 1, the section of the feed is filled with a circular composite material which keep the feeding area protected, and thus give strength to the overall assembly. The geometry of this antenna, which is a cylindrical tube structure, is fully described by parameters, such as length of tube, radius of tube, feeding gap, difference between the diameter of two concentric poles and distance between the connector and lower pole.

The design antenna is simulated using CST microwave studio. The optimum design dimensions are $L_{1}=65 \mathrm{~mm}$ which is length of longer dipole and $L_{2}=42 \mathrm{~mm}$ which is the length of 
shorter pole. The Diameter of the first dipole is $D_{1}=7 \mathrm{~mm}$ while that of the second dipole is $D_{2}=$ $15 \mathrm{~mm}$ and the spacing between the two poles is $S=5 \mathrm{~mm}$. The two different tube dipoles realize the multi-band characteristics. By properly adjusting the length, spacing and diameter of the poles the required bands related to the mobile communication are optimized. The band notch characteristics depend on the difference in length of the two poles. If we decrease the value of $L_{2}$ the notch band increases. The bandwidth can also be increased by increasing the diameter of the hallow cylinders. The bands can be transformed to any other band by adjusting the length according to the band requirements. The antenna is enclosed in epoxy radome which also affects the operating frequency band. The thickness of the radome materials degrade the radiation performance and also change the band to lower side. Furthermore, the distance between radiating poles and radome also affect the gain and decrease the band downwards, so to design the antenna radome effects should be included.

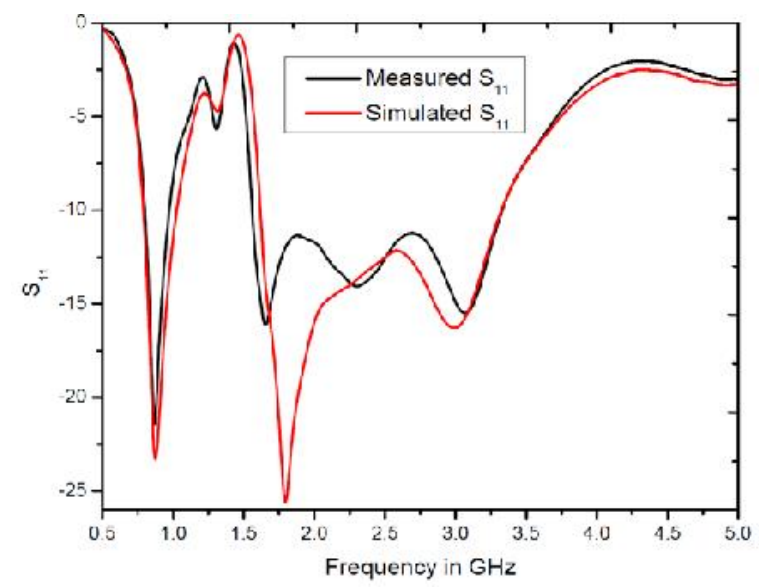

Figure 2. Plot of the measured and simulated scattering parameter $\mathrm{S} 11$ of the sleeve dipole antenna

\section{Results and Analysis}

The Measured and simulated scattering parameter S11 of the proposed antenna is given in the Figure 2. In Figure 2, it is clearly seen that the measured double frequency bands with return loss less than $10 \mathrm{~dB}$ are from $0.7 \mathrm{GHz}$ to $1 \mathrm{GHz}$ for the lower frequency and from 1.7 $\mathrm{GHz}$ to $3.5 \mathrm{GHz}$ for the higher frequency separately, which cover GSM/DCS/WCDMA/CDMA2000/TD-SCDMA /WLAN bands.

The far field radiation characteristics have also been studied. Figure 3 and Figure 4 illustrate the simulated and measured radiation patterns of the proposed antenna at frequencies $0.9 \mathrm{GHz}, 1.8 \mathrm{GHz}$, separately, which displays the E-plane radiation patterns (xy plane) and the $\mathrm{H}$-plane radiation patterns ( $\mathrm{xz}$ plane), respectively. As expected, very good omni-directional patterns are obtained for all frequency bands in the $\mathrm{H}$ planes and the $\mathrm{E}$ planes. The radiation characteristics shows that as the frequency increase ripples are introduced in the radiation pattern. Overall, the measured and simulated radiation pattern are in good agreement. The band 1-1.7 GHz has been notched [5]. The wireless communication in this band is not jammed when the antenna is used as a jammer applications. The difference between the fabrication and simulated plots are due to the different environments, but for all practical applications it is acceptable. Remote activation of improvised explosive devices (IEDs) using commercial mobile devices are used by insurgents and terrorists in many areas all over the world. To encounter these threats military forces mostly use Mobile jammer installed on vehicle. The proposed antenna is suitable for onboard applications. The antenna can be also used in indoor environment in places like hospitals, libraries, mosques, churches concert halls, meeting rooms, and other public places where mobile phone is not allowed to use or ringing is prohibited. 

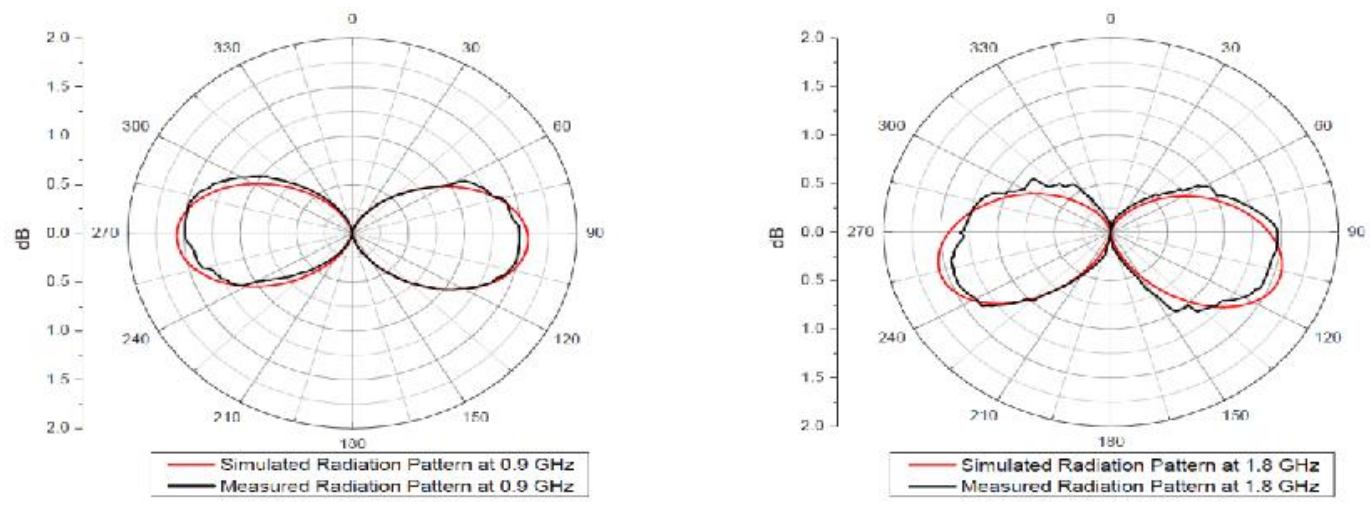

Figure 3. Comparison of the Simulation and Measured Radiation Pattern at $0.9 \mathrm{GHz}$, and 1.8 $\mathrm{GHz}$ in $\mathrm{E}$ plane
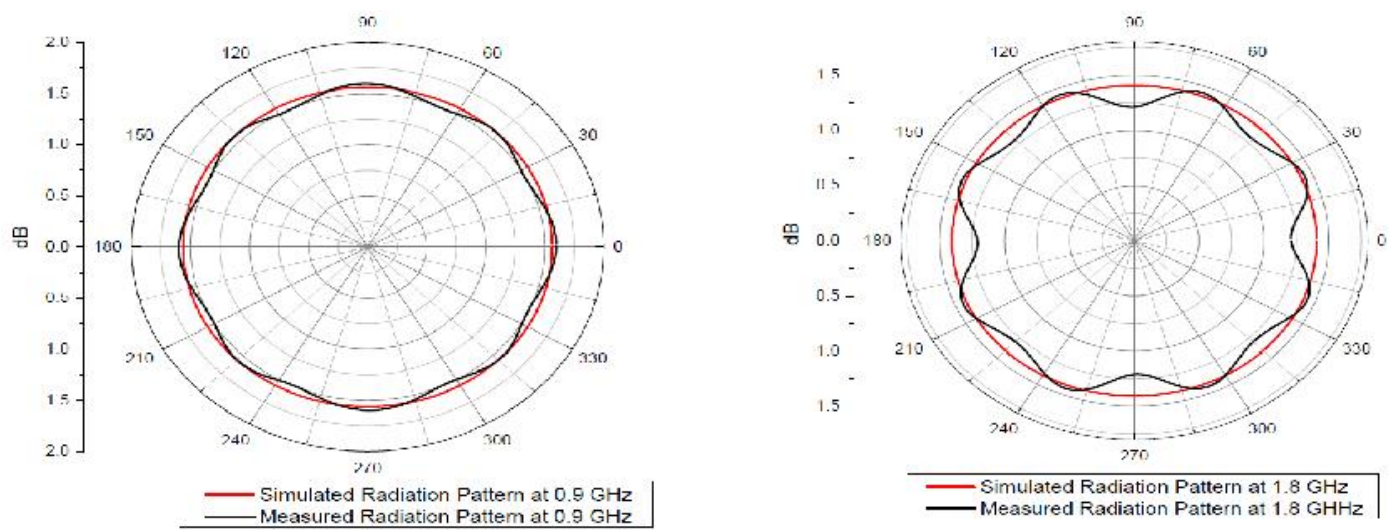

Figure 4. Comparison of the Simulation and Measured Radiation Pattern at $0.9 \mathrm{GHz}$, and 1.8 $\mathrm{GHz}$ in $\mathrm{H}$ plane

\section{Conclusion}

The sleeve dual band dipole antenna represents a very practical means of realizing vertical polarization with an omni-directional pattern and high gain on both lower and upper band which cover all the bands related to mobile communications. The antenna feed by a coaxial cable can handle high power and suitable and can be used both in transmitting and receiving mode. As the antenna is enclosed in radome, so it can be installed on both outdoor and indoor platform and much suitable for vehicular applications. The antenna can handle high power and the feed is protected from the Direct current which can be generated on the body on which the antenna is mounted. The antenna have excellent mechanical and environmental properties to coup with hard condition, and thus can also be used on UAV and low speed aircraft.

\section{References}

[1] Donga YX, Songa LY, Tang LQ, Yuan LC. Analysis and experimental investigation on a novel wideband sleeve dipole array antenna. Int. J. Electron. Commun. 2011; 65(4): 373-376.

[2] Spence TG, Werner DH. A novel miniature broadband/multiband antenna based on an end loaded planar open-sleeve dipole. IEEE Trans. Antennas Propag. 2006; 54(12): 3614-3620.

[3] Schantz HG, Beeler W, Dickson D. UWB planar bulbous dipole antennas. IEEE Antennas Propag. Soc. Int. Symp. Washington, DC. 2005; 2A: 475-478.

[4] Low XN, Chen ZN, See TSP. A UWB dipole antennawith enhanced impedance and gain performance. IEEE Trans. Antennas Propag. 2009; 57(10): 2959-2966.

[5] Ding Y, Weigang Z, Guitao X, Longjun Z. A Novel Omni-Directional UWB Biconical Antenna with Band Notched. IEEE CIE International Conference on Radar. Chengdu. 2011; 2: 1172-1175. 
[6] Thomas KG, Lenin N, Sreenivasan M. Wide-band dual sleeve antenna. IEEE Trans. Antennas Propag. 2006; 54(3): 1034-1037.

[7] Luhaib SW, Quboa KM, Abaoy BM. Design and simulation dual-band PIFA antenna for GSM systems 9th Int Conf on System, Signal and devices Chemnitz. 2012; 1: 1-4.

[8] Rozi F, Khayam U. Design, implementation and testing of triangle, circle, and square shaped loop antennas as partial discharge sensor. ICPERE. Bali. 2014.

[9] Zhao Q, Gong SX, Jiang W, Yang B, Xie J. Compact wide-slot tri-band antenna for WLAN/WiMAX applications. Progress In Electromagnetics Research Letters. 2010; 18: 9-18.

[10] Bao J, Huang Q, Wang X, Shi X. Compact multiband slot antenna for WLAN/WiMAX operations. International Journal of Antennas and Propagation. 2014.

[11] Tariq R, Arshad W, Jiaodong X. Design of Radome Enclosed Omnidirectional Antenna for Airborne Applications. SOP Transactions on Wireless Communications. 2014; 1(2): 51-55.

[12] Kaur J, Khanna R. Development of dual-band microstrip patch antenna for WLAN/MIMO/WIMAX/AMSAT/WAVE applications. Microwave and Optical Technology Letters. 2014; 56(4): 988-993.

[13] Bharti PK, Pandey GK, Singh HS, Meshram MK. A Compact Multiband Planar Monopole Antenna for Slim Mobile Handset Applications. PIER B. 2014; 61 31-42.

[14] Liang JX, Chiau CC, Chen X, Parini CG. Study of a printed circular disc monopole antenna for UWB systems. IEEE Trans. Antennas Propag. 2005; 53(11): 3500-3504.

[15] Chen ZN, Chia MYZ, Ammann MJ. Optimization and comparison of broadband monopoles. Proc. Inst. Elect. Eng. Microw. Antennas Propag. 2003; 150(6): 429-435.

[16] Seko MH, Correra FS. A novel tri-band planar inverted-F antenna for GSM/DCS/PCS operation in mobile handsets. Microwave Opt. Technol. Lett. 2013; 55(4: 821-825.

[17] Kuo YL, Wong KL. Coplanar waveguide-fed folded inverted-F antenna for UMTS application. Microwave Opt. Technol. Lett. 2002; 32(5): 364-366.

[18] Chiu CW, Chi YJ. Planar hexa-band inverted-F antenna for portable device applications. IEEE Antennas Wireless Prop. Lett. 2009; 8: 1099-1102.

[19] Kim KH, Kim JU, Park SO. An ultrawide-band double discone antennawith the tapered cylindrical wires. IEEE Trans. Antennas Propag. 2005; 53(10): 3403-3406.

[20] Asghar AM, Malick M, Karlsson M, Hussain A. A multiwideband planar monopole antenna for 4G devices. Microwave Opt. Technol. Lett. 2013; 55(3): 589-593.

[21] Sultan KS, Abdullah HH, Abdallah EA, Hashish EA. Low-SAR, miniaturized printed antenna for mobile, ISM, and WLAN services. IEEE Antennas and Wireless Prop. Lett. 2013; 12: 1106-1109.

[22] Y Deshan Y, John M Bertram JM, Mark C Converse MC, O Rourke AP, Webster JG, Hagness SC, Will JA, Mahvi DM. A Floating Sleeve Antenna Yields Localized Hepatic Microwave Ablation. IEEE Transactions on Biomedical Engineering. 2006; 53(3): 533-537.

[23] Oraizi H, Jam S. Optimum design of tapered slot antenna prole. IEEE Trans. Antennas Propag. 2003; 51(8): 1987-1995.

[24] Liu YF, Lan KL, Xue Q, Chan CH. Experimental studies of printed wide-slot antenna for wide-band applications. IEEE Antennas Wireless Propag. Lett. 2004; 3(1): 273-275.

[25] Chen ZN, Wu X, Li H, Yang N, Chia MYW. Considerations for source pulses and antennas in UWB radio systems. IEEE Trans. Antennas Propag. 2004; 52(7): 1739-1748.

[26] Cho YJ, Kim KH, Choi DH, Lee SS, Park S. A miniature UWB planar monopole antenna with 5-GHz band rejection filter and the time-domain characteristics. IEEE Trans. Antennas Propag. 2006; 54(5): 1453-1460.

[27] Ashish S, Kamakshi M, Aneesh, Ansari JA. Slots, and Notches Loaded Microstrip Patch Antenna for Wireless Communication. TELKOMNIKA Indonesian Journal of Electrical Engineering. 2015; 13(3): 584-594.

[28] Xue JB, He FJ, Wang D. Analysis and Design of Tag Antenna Based UHF RFID for Libraries. TELKOMNIKA Indonesian Journal of Electrical Engineering. 2015; 13(3): 521-528. 